\title{
Coronary Artery Disease and Atherosclerotic Risk Factors in a Population-Based Study of Sudden Death
}

\author{
Golsa Joodi, MD, $M P H^{7}$, Joan A. Maradey, $\mathrm{MD}^{2}$, Brittany Bogle, $\mathrm{PhD}, \mathrm{MPH}^{3}$, \\ Mojtaba Mirzaei, MD, MPH', Murrium I. Sadaf, MD ${ }^{5}$, Irion Pursell, RN, BSN', \\ Cory Henderson, $\mathrm{MD}^{4}$, John Paul Mounsey, BM BCh, PhD 6 , and Ross J. Simpson Jr, \\ $M D, P h D^{4}$
}

\begin{abstract}
${ }^{1}$ Department of Internal Medicine, Yale University School of Medicine, New Haven, CT, USA; ${ }^{2}$ Department of Internal Medicine, Section on Cardiovascular Medicine, Wake Forest School of Medicine, Winston-Salem, NC, USA; ${ }^{3}$ Senior Data Scientist, Data Science Elite Team, IBM Corporation, Durham, NC, USA; ${ }^{4}$ Division of Cardiology, Department of Medicine, University of North Carolina, Chapel Hill, NC, USA; ${ }^{5}$ Department of Internal Medicine, Yale University School of Medicine, Waterbury, CT, USA; ${ }^{6}$ Department of Cardiovascular Sciences, Brody School of Medicine, East Carolina University, Greenville, NC, USA.
\end{abstract}

BACKGROUND: Sudden death is a public health problem with major impact on society. Coronary artery disease (CAD) is believed to underlie $60-80 \%$ of these deaths. While deaths from CAD have decreased in the recent decades, sudden death rates remain unacceptably high. OBJECTIVE: We aimed to assess the prevalence of CAD and its risk factors among 18-64-year-old adults in a population-based case registry of sudden deaths and compare them to a living population from the same geographical area.

DESIGN: From 2013 to 2015, all sudden deaths among 18-64-year-old adults in Wake County, NC, were identified ( $n=371)$. A comparison group was formed by randomly selecting individuals from an electronic health record repository of a major healthcare system in the area $(N$ $=4218$ ).

MAIN MEASURES: Prevalence of CAD and its risk factors among cases of sudden death and living population across sex and age groups. Odds of sudden death associated with atherosclerotic risk factors and comorbidities.

KEY RESULTS: CAD was present in $14.8 \%$ of sudden death cases. Among sudden death victims, most risk factors and comorbidities were more common in the older age group, except for obesity which was more common in younger cases, and diabetes which was equally prevalent in younger and older cases. Compared to living population, sudden death cases had higher prevalence of atherosclerotic risk factors across all gender and age groups. Sudden death cases had a numerically higher number of risk factors compared to living population, regardless of age group or presence of CAD.

CONCLUSIONS: Coronary artery disease is not common among sudden death cases, but risk factors and

Prior presentations: Preliminary results of this analysis were presented as an abstract at European Society of Cardiology (ESC) 2016 meeting, Rome, Italy, August 27-31, 2016.

Electronic supplementary material The online version of this article (https://doi.org/10.1007/s11606-019-05486-6) contains supplementary material, which is available to authorized users.

Received February 14, 2019

Accepted September 23, 2019

Published online December 5, 2019 comorbidities are prevalent. Our findings support the changing etiology of sudden death. In the absence of clinically diagnosed CAD, use of novel imaging modalities and biomarkers may identify high-risk individuals and lead to prevention of sudden death.

KEY WORDS: coronary artery disease; sudden death; cardiovascular risk factor; SUDDEN.

J Gen Intern Med 35(2):531-7

DOI: $10.1007 / \mathrm{s} 11606-019-05486-6$

(c) Society of General Internal Medicine 2019

\section{INTRODUCTION}

Sudden death remains a major public health challenge, accounting for 15-20\% of mortality from natural causes in developed countries. ${ }^{1,2}$ Survival following sudden cardiac arrest is poor ${ }^{3}$; therefore, reducing sudden death mortality largely hinges upon prevention. ${ }^{4}$ Based on previous studies of adults, coronary artery disease $(\mathrm{CAD})$ contributes up to $80 \%$ of sudden deaths. ${ }^{5}$ Over the last 3 decades, important changes in primary prevention and management of CAD have resulted in a considerable decrease in CAD deaths. ${ }^{6}$ However, the decrease in sudden deaths has not been as steep. ${ }^{7}$ There is also growing evidence that the proportion of sudden deaths attributable to CAD has decreased over the last 15 years, and other proximate causes of sudden death have been suggested. ${ }^{8}$ In order to elucidate these gaps, we assessed the prevalence of diagnosed CAD, as well as atherosclerotic cardiovascular risk factors, using data from a recent population-based case registry of sudden deaths. We compared the prevalence of $\mathrm{CAD}$ and its risk factors to a randomly selected adult population from the same geographical area and time period.

\section{METHODS}

Sudden unexpected death in North Carolina (SUDDEN) is a population-based, case registry of out-of-hospital sudden, natural deaths in Wake County, NC. The present analysis 
assessed sudden death data among individuals 18-64 years of age from the first 2 years of the study (2013-2015). Detailed methods and adjudication process are described elsewhere. ${ }^{9}$ Briefly, Emergency Medical Services (EMS) patient care reporting software (ESO Solutions V 4.8, Austin, TX) was queried electronically to identify EMS attended, out-ofhospital deaths in Wake County. Using information from the EMS event narrative, two trained research assistants independently applied the exclusion criteria (age $<18$ or $>64$, nonnatural mode of death, residents of institutions such as nursing facilities and prisons). Post mortem records (medical examiner's body examinations, toxicology reports, and autopsies) were obtained from the NC Office of the Chief Medical Examiner. Area hospitals and providers were contacted to request clinical records, with follow-up contact at specific intervals. Using all available information, three cardiologists unaffiliated with the study at the University of North Carolina (UNC) at Chapel Hill, adjudicated sudden death cases (Fig. 1). Deaths were considered sudden and unexpected if the circumstances surrounding the event suggested an abrupt pulseless condition in the absence of terminal disease such as cancers, or nonnatural death (overdose, suicide, trauma). No criteria based on the presence of prior cardiac disease, resuscitation, or timing since last seen alive were employed. Majority opinion resolved disagreements. Of 1592 EMS attended out-ofhospital deaths, 399 were adjudicated as sudden death. Those with information on their medical history, either from clinical records within 5 years prior to death or medical examiner's report $(n=371,93 \%)$ were included in this analysis.
A control group of randomly sampled patients from The Carolina Data Warehouse for Health (CDW) was formed. The $\mathrm{CDW}$ is a central electronic health records repository containing clinical, research, and administrative data from 18 hospitals and practices within the University of North Carolina Health Care Systems. ${ }^{10}$ Five years of medical records were obtained on 15,000 randomly selected 18-64-year-old individuals who attended UNC hospitals or practices for an inpatient or outpatient visit between March 1, 2013, and February 28, 2015 (index visit). To emulate the SUDDEN study population, individuals were included in the present study if the physical home address was in Wake County, NC $(N=4982)$, and were excluded if resided or discharged to an institution $(N$ $=764$ ), for a final control group of 4,218 patients. Given methodological complexity, appropriateness of control group selection was discussed with local experts at UNC as well as project data scientist (BB). This comparison group is intended to represent the general population of similar age group in the same geographical area. Demographic variables, including race, were matched between cases and controls.

For cases, demographic data were obtained from electronic death certificates obtained through $\mathrm{NC}$ vital records. Information on comorbidities such as dyslipidemia, diabetes mellitus (DM), hypertension, $\mathrm{CAD}$, heart failure (HF), chronic kidney disease (CKD), and stroke was manually abstracted from medical records according to detailed protocols. Smoking history and body mass index (BMI) $\left(\mathrm{kg} / \mathrm{m}^{2}\right)$ were obtained from the most recent record available, and obesity was defined as BMI greater than 30. Clinical history of CAD was defined as a physician's diagnosis of CAD, prior myocardial

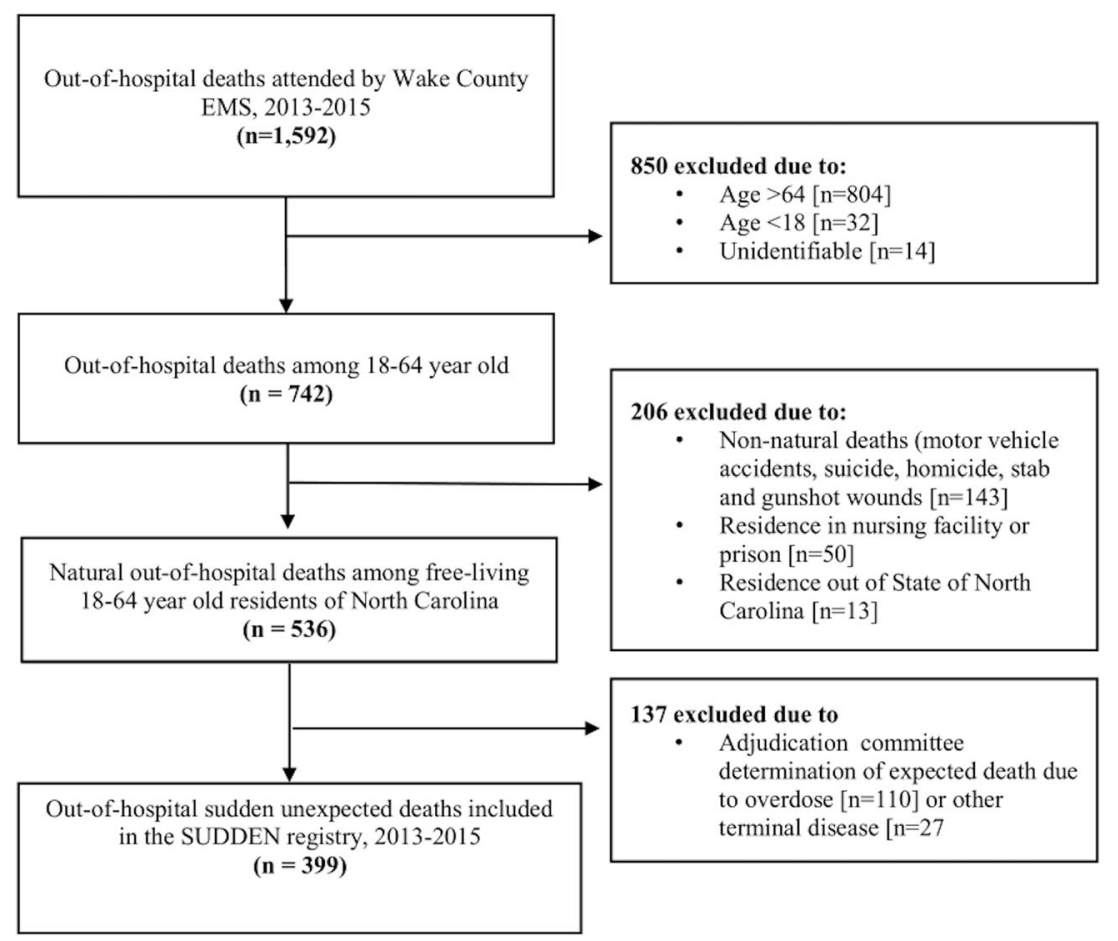

Figure 1 Details of case ascertainment and identification of sudden deaths in Wake County, North Carolina. EMS, emergency medical services; SUDDEN, sudden unexpected death in North Carolina. 
infarction, or coronary revascularization (percutaneous coronary intervention or coronary artery bypass graft). Reliability of the abstraction process was checked via blind re-abstraction of a $15 \%$ sample of cases by quality assurance committee. For controls, race and sex were queried from electronic medical records, and age was calculated by subtracting the date of the index visit from the date of birth. Electronic medical records prior to or at the index visit were queried for any International Classification of Diseases-9 (ICD-9) codes identifying diagnoses of dyslipidemia, DM, hypertension, CAD, stroke, CKD, and HF. Smokers were identified as individuals with a history of smoking within five years preceding the index visit, and BMI was calculated from most recent available height and weight (see Supplemental Table 1 for criteria for specific terms (cases) and ICD9 codes (controls) used to abstract covariates).

Demographic and clinical characteristics were summarized using frequencies for categorical variables and mean and SD for continuous variables. Cases and controls were categorized into two age groups of younger (18-54-year-old) and older (55-64-year-old) subjects. Prevalence of risk factors and conditions were compared between cases and controls, stratified by sex and age group, using a chi-square test. Logistic regression was performed to calculate the age-adjusted odds of sudden death associated with each covariate, stratified by sex. The mean number of comorbid risk factors were compared between cases and controls using a $t$ test with pooled two-sample equal variance. For all analyses, a $p$ value $<0.05$ was considered statistically significant. Statistical analyses were performed using SAS version 9.3 (SAS institute Inc., Cary, North Carolina). This project was reviewed by the University of North Carolina's institutional review board and found to be exempt (study \#: 13-2445). The study was given expedited review as it was deemed low risk with appropriate safeguards for confidentiality.

\section{RESULTS}

Demographic and clinical characteristics of the sudden death cases are presented in Table 1. Overall, mean age was 52.7 (SD 9.4), 254 (68.5\%) of subjects were male, 234 (63\%) were white, and $124(33 \%)$ were black. Approximately half $(n=174,46 \%)$ of cases were 18-54 years old, and 53\% were 55-64 years old. These age groups were chosen for subsequent analysis. Overall, $14.8 \%$ of sudden death victims had history of CAD $(16.5 \%$ in men, $11.1 \%$ in women) and was more common among older cases $(18.8 \%$ vs. $10.3 \%)$. Most risk factors (smoking, hypertension, dyslipidemia) as well as comorbidities (DM, HF, CKD) were more common among older cases. Obesity was more common in the younger cases (50\% vs $34.5 \%$ ), and diabetes was equally prevalent in young and old cases ( $25 \%$ vs $33 \%)$.

The prevalence of risk factors and comorbidities were compared among the cases and controls stratified by sex and age group (Table 2). Among men, cases had a higher prevalence of hypertension, dyslipidemia, DM, CKD, CAD, and $\mathrm{HF}$
Table 1 Demographic and Clinical Characteristics of Victims of Sudden Death in Wake County, North Carolina

\begin{tabular}{|c|c|c|c|c|}
\hline & $\begin{array}{l}\text { Age } \\
18-54 \\
(n= \\
174)\end{array}$ & $\begin{array}{l}\text { Age } \\
55-64 \\
(n= \\
197)\end{array}$ & $\begin{array}{l}\text { All subjects } \\
(n=371)\end{array}$ & $\begin{array}{l}p \\
\text { value* }\end{array}$ \\
\hline Age, mean (SD) & $45(8.1)$ & $\begin{array}{l}59.5 \\
(2.8)\end{array}$ & $52.7(9.4)$ & - \\
\hline Male, $n(\%)$ & $\begin{array}{l}124 \\
(71.3)\end{array}$ & $130(66)$ & $254(68.5)$ & 0.275 \\
\hline $\begin{array}{l}\text { Race-ethnicity, } \\
n(\%)\end{array}$ & & & & 0.550 \\
\hline White & $\begin{array}{l}111 \\
(63.8)\end{array}$ & $\begin{array}{l}123 \\
(62.4)\end{array}$ & $234(63)$ & \\
\hline African American & $\begin{array}{l}55 \\
(31.6)\end{array}$ & $69(35)$ & $124(33.4)$ & \\
\hline $\begin{array}{l}\text { Other } \\
\text { Unknown }\end{array}$ & $\begin{array}{l}7(4) \\
1(0.5)\end{array}$ & $5(2.5)$ & $\begin{array}{l}12(3.2) \\
1(0.2)\end{array}$ & \\
\hline $\begin{array}{l}\text { Witnessed arrest, } \\
n(\%)\end{array}$ & $\begin{array}{l}23 \\
(13.2)\end{array}$ & $16(8.1)$ & $39(10.5)$ & 0.110 \\
\hline $\begin{array}{l}\text { Resuscitation } \\
\text { attempted, } n(\%) \\
\text { Smoking status }{ }^{\dagger}, \\
n(\%)\end{array}$ & $\begin{array}{l}71 \\
(40.8)\end{array}$ & $\begin{array}{l}76 \\
(38.6)\end{array}$ & 147 (39.6) & 0.662 \\
\hline $\begin{array}{l}\text { Current/former } \\
\text { smoker }\end{array}$ & $\begin{array}{l}69 \\
(60.5)\end{array}$ & $\begin{array}{l}104 \\
(72.7)\end{array}$ & $173(67.3)$ & 0.038 \\
\hline Never smoker & $\begin{array}{l}45 \\
(39.5)\end{array}$ & $\begin{array}{l}39 \\
(27.3)\end{array}$ & $84(32.7)$ & \\
\hline Unknown & 60 & 54 & 114 & \\
\hline $\begin{array}{l}\text { Obesity }{ }^{\dagger+} \\
n(\%)\end{array}$ & $69(50)$ & $\begin{array}{l}58 \\
(34.5)\end{array}$ & $127(41.5)$ & 0.006 \\
\hline $\begin{array}{l}\text { Hypertension, } \\
n(\%)\end{array}$ & $94(54)$ & $130(66)$ & $224(60.4)$ & 0.019 \\
\hline $\begin{array}{l}\text { Dyslipidemia, } \\
n(\%)\end{array}$ & $\begin{array}{l}50 \\
(28.7)\end{array}$ & $\begin{array}{l}96 \\
(48.7)\end{array}$ & $146(39.4)$ & $\begin{array}{l}< \\
0.001\end{array}$ \\
\hline $\begin{array}{l}\text { Diabetes mellitus, } \\
n(\%)\end{array}$ & $\begin{array}{l}44 \\
(25.3)\end{array}$ & $65(33)$ & $109(29.4)$ & 0.104 \\
\hline $\begin{array}{l}\text { Coronary artery } \\
\text { disease }^{\S}, n(\%)\end{array}$ & $\begin{array}{l}18 \\
(10.3)\end{array}$ & $\begin{array}{l}37 \\
(18.8)\end{array}$ & $55(14.8)$ & 0.022 \\
\hline Stroke, $n(\%)$ & $6(3.5)$ & $\begin{array}{l}20 \\
(10.1)\end{array}$ & $26(7)$ & 0.012 \\
\hline $\begin{array}{l}\text { Heart failure, } \\
n(\%)\end{array}$ & $15(8.6)$ & $\begin{array}{l}36 \\
(18.3)\end{array}$ & $51(13.8)$ & 0.007 \\
\hline $\begin{array}{l}\text { Chronic kidney } \\
\text { disease, } n(\%)\end{array}$ & $13(7.5)$ & $\begin{array}{l}31 \\
(15.7)\end{array}$ & $44(11.9)$ & 0.014 \\
\hline
\end{tabular}

ME Medical examiner

*P values from Pearson's chi-square test comparing frequencies between age groups 18-54 and 55-64

tFor variables with missing values, proportions and $p$ values are calculated using the non-missing data as the denominator

$\neq$ Body mass index (BMI) was not available in 36 and 29 cases in 18-54 and 55-64 age group respectively

compared to living controls in both age groups. There was no significant difference in the prevalence of obesity between cases and controls in either age group. Smoking and history of stroke were more prevalent only in older cases compared to their living controls. Among women, smoking, hypertension, dyslipidemia, DM, CKD, CAD, HF, and stroke were more prevalent in cases compared to controls in both age groups. Obesity was more prevalent in the younger cases compared to controls and was equal between older cases and controls.

Figure 2 displays the number of coexisting atherosclerotic risk factors in cases and controls. Living controls on average had 1 (SD 1.2) risk factors compared to cases 2.2 (SD 1.0). Cases with CAD had more risk factors compared to cases without CAD. In both age groups, cases had higher number of atherosclerotic risk factors compared to their living controls, regardless of CAD status. 
Table 2 Comparison of Clinical Characteristics Between Sudden Death Cases and Controls in Wake County, North Carolina, Stratified by Age Group and Sex

\begin{tabular}{|c|c|c|c|c|c|c|}
\hline \multirow[b]{2}{*}{ Men } & \multicolumn{3}{|l|}{ Age 18-54 } & \multicolumn{3}{|l|}{ Age 55-64 } \\
\hline & Cases $(n=124)$ & Controls $(n=1071)$ & $p$ value* & Cases $(n=130)$ & Controls $(n=505)$ & $p$ value* \\
\hline Smoking ${ }^{\dagger}, \%$ & 38.7 & 31.5 & 0.1022 & 58.5 & 39.2 & $<0.001$ \\
\hline Obesity ${ }^{\dagger *}, \%$ & 47 & 37.5 & 0.062 & 36.0 & 41.4 & 0.305 \\
\hline Hypertension, \% & 52.4 & 16.3 & $<0.001$ & 65.4 & 38.8 & $<0.001$ \\
\hline Dyslipidemia, \% & 29.8 & 13.0 & $<0.001$ & 49.2 & 27.7 & 0.012 \\
\hline Diabetes mellitus, \% & 21.8 & 5.9 & $<0.001$ & 34.6 & 15.5 & $<0.001$ \\
\hline Coronary artery disease, $\%$ & 10.5 & 2.2 & $<0.001$ & 22.3 & 8.3 & $<0.001$ \\
\hline Heart failure, \% & 9.7 & 1.0 & $<0.001$ & 15.4 & 3.6 & $<0.001$ \\
\hline Chronic kidney disease, \% & 7.3 & 1.3 & $<0.001$ & 18.5 & 4.0 & $<0.001$ \\
\hline Stroke, \% & 2.4 & 0.8 & 0.095 & 11.5 & 2.4 & $<0.001$ \\
\hline Women & Cases $(n=50)$ & Controls $(n=1810)$ & $p$ value* & Cases $(n=67)$ & Controls $(n=832)$ & $p$ value* \\
\hline Smoking ${ }^{\dagger}, \%$ & 42 & 18.9 & $<0.001$ & 41.8 & 29.9 & 0.043 \\
\hline Obesity ${ }^{1 *}, \%$ & 57.9 & 36.0 & 0.006 & 31.6 & 40 & 0.212 \\
\hline Hypertension, \% & 58 & 11.1 & $<0.001$ & 67.2 & 24.4 & $<0.001$ \\
\hline Dyslipidemia, \% & 26 & 5.1 & $<0.001$ & 47.8 & 16.47 & $<0.001$ \\
\hline Diabetes mellitus, \% & 34 & 4.3 & $<0.001$ & 29.9 & 9.6 & $<0.001$ \\
\hline Coronary artery disease, $\%$ & 10 & 0.66 & $<0.001$ & 11.9 & 1.8 & 0.001 \\
\hline Heart failure, $\%$ & 6 & 0.83 & $<0.001$ & 23.9 & 1.1 & $<0.001$ \\
\hline Chronic kidney disease, \% & 8 & 0.88 & $<0.001$ & 10.5 & 2.5 & $<0.001$ \\
\hline Stroke, $\%$ & 6 & 0.72 & $<0.001$ & 7.5 & 1.44 & $<0.001$ \\
\hline
\end{tabular}

*P values from Pearson's chi-square test comparing frequencies between cases and controls

FFor variables with missing values, proportions and $p$ values are calculated using the non-missing data as the denominator

$\neq$ Body mass index (BMI) was missing for 36 and 29 cases and 504 and 252 controls, in 18-54 and 55-64 age group respectively

Except for obesity, all other risk factors and comorbidities were associated with sudden death (Table 3). Odds ratios (ORs) for all risk factors were higher for women compared to men, and highest ORs were seen with HF (5.5 95\% CI 3.29.5 in men and $12.895 \%$ CI 6.5-25.5 in women).

\section{DISCUSSION}

In our population-based study of sudden death, we found coronary disease to be present in only $14.8 \%$ of cases. Compared to the controls, cases on average had more atherosclerotic risk factors, across all sex-age categories.

The $14.8 \%$ prevalence of clinically diagnosed CAD in victims of sudden death is close to $22-35 \%$ rate reported in previous studies of similar age group. ${ }^{11,12}$ While this rate is lower than expected based on the general belief that CAD accounts for $60-80 \%$ of sudden deaths, temporal trends support our observation. A prospective longitudinal study showed a decline in the proportion of sudden deaths related to CAD, and a concomitant increase in the proportion of non-ischemic sudden deaths (related to hypertensive heart disease and idiopathic fibrosis). ${ }^{8}$ Our data suggests that $\mathrm{CAD}$ may no longer be the dominant cause of sudden death, as it was in the past.

Subclinical myocardial injury and ischemia secondary to hypertension and diabetes, which were highly prevalent among victims, may directly account for our low rate of CAD. ${ }^{13,14}$ Dysfunction of coronary microvasculature, also linked to obesity and hypertension, has been shown to affect the myocardial blood flow even in the absence of obstructive CAD. Finally, non-ischemic heart disease may also have played a role, as they have been shown to be associated with sudden death. ${ }^{15-17}$ In an autopsy series of sudden death, more than half of subjects who did not have CAD had signs of left ventricular hypertrophy, interstitial fibrosis, and cardiomegaly. ${ }^{18}$ Left ventricular hypertrophy and interstitial fibrosis are established consequences of hypertension and obesity ${ }^{19}$, 20 and have been associated with ventricular tachycardia in both ischemic and non-ischemic heart disease. ${ }^{21,} 22$ Furthermore, recent studies have demonstrated the role of structural cardiac changes in SCD, in the absence of obstructive CAD. The Rotterdam Study found subclinical abnormalities in systolic function were associated with increased risk of sudden death. ${ }^{16} \mathrm{~A}$ meta-analysis of Atherosclerosis Risk in Communities Study and Cardiovascular Health Study participants, found mitral annular calcification, increased LV mass, and increased left atrial diameter, to be predictors of sudden death. ${ }^{15}$

The prevalence of cardiovascular risk factors among our cases are comparable to those reported in previous studies. In the Atherosclerosis Risk in Communities Study, hypertension, DM, and HF was present in $63.3 \%, 34.9 \%$, and $11.6 \%$ among $\mathrm{SCDs},{ }^{23}$ compared to $60.4 \%, 29.4 \%$, and $13.8 \%$ in our study, respectively. Similarly, the Oregon Sudden Unexpected Deaths study reported hypertension and DM in $52.2 \%$ and $29.1 \%$ of cases 35-60 years of age, ${ }^{12}$ and history of stroke, chronic renal disease, and dyslipidemia in $6.9 \%, 13.9 \%$, and $33.7 \%$ of cases, compared to $7 \%, 12 \%$, and $39.4 \%$ in our study.

Low rates of CAD among sudden death cases, in spite of a high prevalence of traditional atherosclerotic risk factors, have important implications for prevention of sudden death. Lifestyle and medical therapy lower 

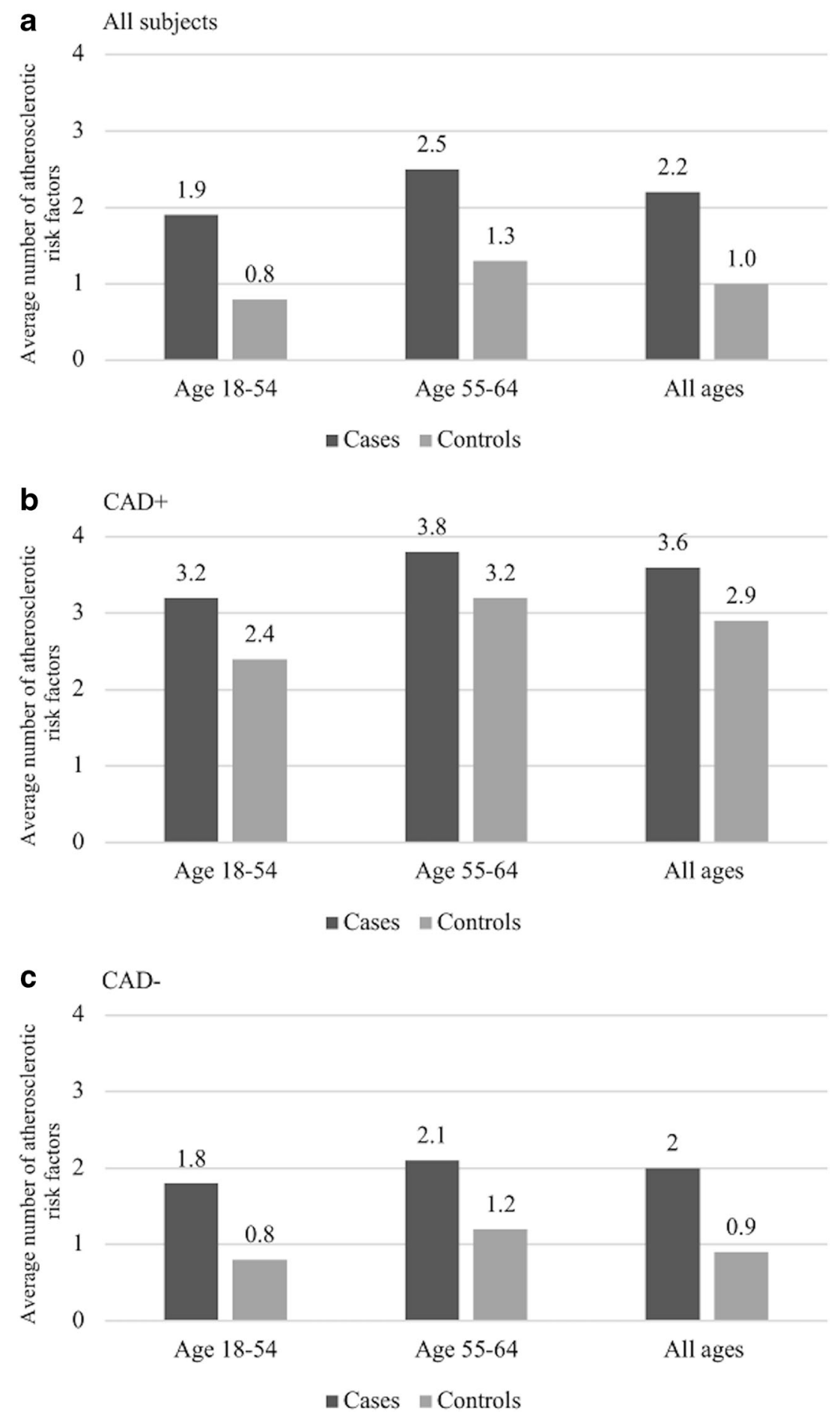

Figure 2 Average number of atherosclerotic cardiovascular disease risk factors in sudden death cases and living controls. Among all subjects (a), those with history of CAD (b), those without history of CAD (c). Atherosclerotic cardiovascular disease risk factors included in this comparison were smoking, obesity, hypertension, diabetes mellitus, dyslipidemia, and chronic renal disease. CAD, coronary artery disease.

sudden death rates in individuals with CAD. ${ }^{24}$ Implementation of such therapy in individuals with subclinical CAD should reduce the risk of sudden death. However, individuals with subclinical or stable CAD are a heterogeneous group, and therefore appropriate risk stratification may be necessary to target those at highest risk. Noninvasive imaging modalities added to traditional risk assessment have improved cardiovascular risk assessment and prediction of future events. ${ }^{25,}{ }^{26}$ Certain imaging modalities are capable of identifying anatomic substrates that are pathophysiologically related to lethal arrhythmias. ${ }^{27-29}$ Novel biomarkers, such as highsensitivity cardiac troponin $\mathrm{T}$ (hs-cTnT) and N-terminal proB-type natriuretic peptide (NT-proBNP), show promise to predict cardiovascular events. ${ }^{30,31}$ 
Table 3 Odds Ratios of Sudden Death Associated with Various Risk Factors and Comorbidities Among Men and Women

\begin{tabular}{lll}
\hline \hline & $\begin{array}{l}\text { Men } \\
\text { Odds ratio (95\% } \\
\text { CI) }\end{array}$ & $\begin{array}{l}\text { Women } \\
\text { Odds ratio (95\% } \\
\text { CI) }\end{array}$ \\
\hline Smoking & $1.6(1.2-2.1)$ & $1.9(1.3-2.8)$ \\
Obesity & $1.0(0.8-1.4)$ & $1.1(0.7-1.8)$ \\
Hypertension & $3.5(2.6-4.7)$ & $6.3(4.2-9.4)$ \\
Dyslipidemia & $2.2(1.6-3.0)$ & $3.8(2.5-5.7)$ \\
Diabetes mellitus & $3.0(2.2-4.2)$ & $5.3(3.4-8.2)$ \\
Coronary artery & $3.0(2.0-4.7)$ & $6.9(3.3-14.1)$ \\
disease & $5.5(3.2-9.5)$ & $12.8(6.5-25.5)$ \\
Heart failure & $5.0(3.0-8.4)$ & $4.6(2.2-9.5)$ \\
Chronic kidney & & $5.9(2.5-14.3)$ \\
disease & $3.9(2.0-7.5)$ & \\
Stroke & &
\end{tabular}

Our study had several limitations. We did not include adults older than 64 years of age in the current study despite known higher risk of sudden death with increasing age. This decision was made based on the guidance from adjudication committee who found it practically challenging to differentiate sudden-ness of death in the older population with higher burden of comorbidities at more advanced stages. In addition, adults younger than 65 have a heterogenous and different healthcare access profile compared to those older than 65 , which can influence the causes of premature mortality. Despite sustained systematic efforts to obtain medical records, the possibility of incomplete records cannot be ruled out for those who had not seen a provider in the past 5 years or their providers failed to provide us with their records. Although Wake County EMS is required to attend most out-of-hospital deaths, we may not have captured the few cases that were not attended by EMS. Strengths of our study include our ascertainment method. Through collaboration of EMS, NC medical examiner's office, and area hospitals and providers, we were able to capture and adjudicate all sudden deaths, without applying preconditions of etiology of death or resuscitation status. Finally, Wake County is a large racially and socioeconomically diverse population, reflected in our study population as well. ${ }^{9}$

In summary, clinical coronary artery disease is not common in sudden death victims but atherosclerotic risk factors are commonly present. Our findings support a changing pattern of etiology of sudden death, with a decline in clinically diagnosed coronary artery disease and presence of a heterogeneous mixture of other etiologies, dictating a more complex approach for prevention. More aggressive diagnostic testing and treatment for subclinical coronary disease, hypertension, high lipids, diabetes, ventricular hypertrophy, and other factors seems to have the potential to prevent sudden death.

Acknowledgments: The Wake County EMS Data System supports, maintains, and monitors EMS service delivery, patient care, and disaster preparedness for the Wake County, NC, community at large. This manuscript has been reviewed by Wake County EMS Data System investigators for scientific content and consistency of data interpretation with previous Wake County EMS Data System publications.

We would like to thank the North Carolina Office of the Chief Medical Examiner, SUDDEN team of researchers, and the Carolina Data Warehouse/North Carolina Translational and Clinical Sciences Institute at University of North Carolina at Chapel Hill.

Corresponding Author: Ross J. Simpson, Jr, MD, PhD; Division of Cardiology, Department of Medicine University of North Carolina, Chapel Hill, NC, USA (e-mail: ross_simpson@med.unc.edu).

Funders The SUDDEN project is funded by individual, private donations, The Heart and Vascular Division of the University of North Carolina at Chapel Hill, and the McAllister Heart Institute. The project described was supported by the National Center for Advancing Translational Sciences (NCATS), National Institutes of Health, through Grant Award Number UL1TR002489. The content is solely the responsibility of the authors and does not necessarily represent the official views of the NIH.

Compliance with Ethical Standards: This project was reviewed by the University of North Carolina's institutional review board and found to be exempt (study \#: 13-2445).

Conflict of Interest: Ross J. Simpson Jr has served as consultant for Amgen, Merck, Pfizer. CEROBS and ISS. All remaining authors declare that they do not have a conflict of interest.

\section{REFERENCES}

1. Kong MH, Fonarow GC, Peterson ED, et al. Systematic review of the incidence of sudden cardiac death in the United States. J Am Coll Cardiol. 2011;57:794-801.

2. Mozaffarian D, Benjamin EJ, Go AS, et al. Heart Disease and Stroke Statistics-2016 Update: A Report From the American Heart Association. Circulation. 2016;133:e38-e360.

3. Sasson C, Rogers MA, Dahl J, Kellermann AL. Predictors of survival from out-of-hospital cardiac arrest: a systematic review and metaanalysis. Circ Cardiovasc Qual Outcomes. 2010;3:63-81.

4. Adabag AS, Luepker RV, Roger VL, Gersh BJ. Sudden cardiac death: epidemiology and risk factors. Nat Rev Cardiol. 2010;7:216-25.

5. Zipes DP, Wellens HJ. Sudden cardiac death. Circulation 1998;98:233451.

6. Ford ES, Ajani UA, Croft JB, et al. Explaining the decrease in U.S. deaths from coronary disease, 1980-2000. N Engl J Med. 2007;356:2388-98.

7. Hayashi M, Shimizu W, Albert CM. The spectrum of epidemiology underlying sudden cardiac death. Circ Res. 2015;116:1887-906.

8. Junttila MJ, Hookana E, Kaikkonen KS, Kortelainen ML, Myerburg RJ, Huikuri HV. Temporal trends in the clinical and pathological characteristics of victims of sudden cardiac death in the absence of previously identified heart disease. Circ Arrhythm Electrophysiol. 2016;9(6):e003723.

9. Mounsey LA, Lin FC, Pursell I, et al. Relation of Household Income to Incidence of Sudden Unexpected Death in Wake County, North Carolina. Am J Cardiol. 2017;119:1030-1035.

10. Carolina Data Warehouse for Health. https://tracs.unc.edu/index.php/ services/informatics-and-data-science/cdw-h. Accessed 28 Nov 2019

11. Gorgels APM, Gijsbers C, de Vreede-Swagemakers J, Lousberg A, Wellens HJJ. Out-of-hospital cardiac arrest-the relevance of heart failure. The Maastricht Circulatory Arrest Registry. Eur Heart J. 2003;24:1204-1209.

12. Noheria A, Teodorescu C, Uy-Evanado A, et al. Distinctive profile of sudden cardiac arrest in middle-aged vs. older adults: a communitybased study. Int J Cardiol. 2013;168:3495-9.

13. Lacourciere Y, Cote C, Lefebvre J, Dumont M. Noninvasive detection of silent coronary artery disease in patients with essential hypertension, alone or associated with type 2 diabetes mellitus, using dipyridamole stress 99mtechnetium-sestamibi myocardial perfusion imaging. Can J Cardiol. 2006;22 Suppl A:16A-21A.

14. O'Neal WT, Shah AJ, Efird JT, Rautaharju PM, Soliman EZ. Subclinical Myocardial Injury Identified by Cardiac Infarction/Injury Score and the 
Risk of Mortality in Men and Women Free of Cardiovascular Disease. Am J Cardiol. 2014; 114:1018-1023.

15. Konety SH, Koene RJ, Norby FL, et al. Echocardiographic Predictors of Sudden Cardiac Death: The Atherosclerosis Risk in Communities Study and Cardiovascular Health Study. Circ Cardiovasc Imaging. 2016;9(8):e004431.

16. Niemeijer MN, Leening MJG, van den Berg ME, et al. Subclinical Abnormalities in Echocardiographic Parameters and Risk of Sudden Cardiac Death in a General Population: The Rotterdam Study. J Card Fail. 2016;22:17-23.

17. Siscovick DS, Raghunathan TE, Rautaharju P, Psaty BM, Cobb LA, Wagner EH. Clinically Silent Electrocardiographic Abnormalities and Risk of Primary Cardiac Arrest Among Hypertensive Patients. Circulation. 1996;94:1329-1333.

18. Adabag AS, Peterson G, Apple FS, Titus J, King R, Luepker RV Etiology of sudden death in the community: results of anatomical, metabolic, and genetic evaluation. Am Heart J. 2010;159:33-9.

19. Alpert MA, Terry BE, Mulekar M, et al. Cardiac Morphology and Left Ventricular Function in Normotensive Morbidly Obese Patients With and Without Congestive Heart Failure, and Effect of Weight Loss. Am J Cardiol. 1997;80:736-740.

20. Ishizu T, Seo Y, Kameda Y, et al. Left Ventricular Strain and Transmural Distribution of Structural Remodeling in Hypertensive Heart Disease. Hypertension. 2014;63(3):500-6.

21. Adabag AS, Maron BJ, Appelbaum E, et al. Occurrence and Frequen cy of Arrhythmias in Hypertrophic Cardiomyopathy in Relation to Delayed Enhancement on Cardiovascular Magnetic Resonance. J Am Coll Cardiol. 2008;51:1369-1374.

22. Shenasa M, Shenasa H. Hypertension, left ventricular hypertrophy, and sudden cardiac death. Int J Cardiol. 2017;237:60-63.

23. Maheshwari A, Norby FL, Soliman EZ, et al. Low Heart Rate Variability in a 2-Minute Electrocardiogram Recording Is Associated with an Increased Risk of Sudden Cardiac Death in the General Population: The
Atherosclerosis Risk in Communities Study. PLoS One. 2016;11:e0161648.

24. Rea TD, Pearce RM, Raghunathan TE, et al. Incidence of Out-ofHospital cardiac arrest. Am J Cardiol. 2004;93:1455-1460.

25. Fernández-Friera L, Ibáñez B, Fuster V. Imaging Subclinical Atherosclerosis: Is It Ready for Prime Time? A Review. J Cardiovasc Transl Res. 2014;7:623-634.

26. Budoff MJ, Gul KM. Expert review on coronary calcium. Vasc Health Risk Manag. 2008;4:315-24.

27. Gao $\mathbf{P}$, Yee R, Gula $\mathbf{L}$, et al. Prediction of arrhythmic events in ischemic and dilated cardiomyopathy patients referred for implantable cardiac defibrillator: evaluation of multiple scar quantification measures for late gadolinium enhancement magnetic resonance imaging. Circ Cardiovasc Imaging. 2012;5:448-56.

28. Macatangay C, Viles-Gonzalez JF, Goldberger JJ. Role of Cardiac Imaging in Evaluating Risk for Sudden Cardiac Death. Card Electrophysiol Clin. 2017;9:639-650.

29. Nazarian S, Bluemke DA, Lardo AC, et al. Magnetic resonance assessment of the substrate for inducible ventricular tachycardia in nonischemic cardiomyopathy. Circulation. 2005;112:2821-5.

30. Lindholm D, Lindbäck J, Armstrong PW, et al. Biomarker-Based Risk Model to Predict Cardiovascular Mortality in Patients With Stable Coronary Disease. J Am Coll Cardiol. 2017;70:813-826.

31. McEvoy JW, Chen Y, Ndumele CE, et al. Six-year change in highsensitivity cardiac troponin $\mathrm{t}$ and risk of subsequent coronary heart disease, heart failure, and death. JAMA Cardiol. 2016;1:519-528.Publisher's Note: Springer Nature remains neutral with regard to jurisdictional claims in published maps and institutional affiliations.

Publisher's Note Springer Nature remains neutral with regard to jurisdictional claims in published maps and institutional affiliations. 